\title{
PERANCANGAN APLIKASI MOBILE UNTUK KONSUMSI CAFFEINE : STUDI KASUS "KOPI JOSS"
}

\author{
I Nyoman Yudi Anggara Wijaya ${ }^{1)}$ Nur Budi Nugraha ${ }^{2)}$ \\ Prodi Sistem Informasi, Sekolah Tinggi Manajemen Informatikan dan Komputer (STMIK) Primakara') \\ Prodi Teknik Industri, Sekolah Tinggi Teknologi Dumai ${ }^{2)}$ \\ inyomanyudi@gmail.com ${ }^{1}$
}

\begin{abstract}
Popularity of Coffee as one of the popular drinks because it has a distinctive taste and aroma. Coffee contains caffeine which is a psychoactive one that is used to reduce fatigue and also relieve drowsiness. Daily caffeine consumption shows that the average person consumes $180.94 \mathrm{mg}$ until $319.32 \mathrm{mg}$ of caffeine per day. Excessive consumption of caffeine can interfere with health. Several studies on coffee have now been carried out by researchers who discuss the benefits of coffee, the benefits of each coffee bean and how to make coffee with the best taste, of course, by doing laboratory testing to get good results. Coffee is the main source of caffeine all over the world. Problems that occur at this time where consumers as fans of coffee sometimes do not know the ideal coffee dose that can be consumed by consumers. Every consumption of coffee has a dose that can affect health. From the problem of the coffee dose, to find out the ideal proportion in joss coffee consumption based on one's weight, a mobile application will be developed that can help users to know the amount of caffeine from ground coffee based on the weight of the coffee, and specifically knowing the ideal amount of coffee consumption based on one's weight. The results of this study are an adroid application design that can be used to calculate coffee that can be consumed by consumers. The purpose of this study is to provide an overview of the amount of coffee that can be consumed and a person's weight.
\end{abstract}

Keywords: Mobile Application, Caffeine Computatition, Kopi Joss, Coffee, Caffeine

\begin{abstract}
ABSTRAK
Popularitas Kopi sebagai salah satu minuman yang digemari masyarakat karena memiliki cita rasa dan aroma yang khas. Kopi mengandung kafein yang merupakan salah satu psikoaktif yang digunakan untuk mengurangi kelelahan dan juga menghilangkan kantuk. Konsumsi kafein harian menunjukkan bahwa rata-rata orang mengkonsumsi 180,94 mg sampai dangan 319,32 mg kafein per hari. Konsumsi caffeine yang berlebihan dapat mengganggu kesehatan. Penelitian tentang kopi saat ini beberapa sudah dilakukan oleh para peneliti yang membahas mengenai manfaat kopi, manfaat masing-masing biji kopi dan bagaimana membuat kopi dengan cita rasa terbaik tentunya dengan melakukan pengujian laboratorium untuk mendapatkan hasil yang baik. Kopi adalah sumber utama kafein seluruh dunia. Permasalahan yang terjadi saat ini dimana konsumen sebagai penggemar kopi terkadang belum mengetahui takaran kopi yang ideal yang dapat dikonsumsi oleh konsumen. Setiap mengkonsumsi kopi memiliki takaran yang dapat mempengaruhi kesehatan. Dari permasalahan takaran kopi tersebut maka untuk mengetahui proporsi yang ideal dalam konsumsi kopi joss berdasarkan berat badan seseorang akan dikembangan aplikasi mobile yang dapat membantu pengguna untuk mengetahui jumlah caffeine dari kopi bubuk berdasarkan berat kopi tersebut, dan kususnya mengetahui jumlah ideal konsumsi kopi berdasarkan berat badan seseorang. Hasil dari penelitian ini adalah sebuah perancangan aplikasi android yang dapat digunakan untuk perhitungan kopi yang dapat dikonsumsi oleh konsumen. Tujuan dari penelitian ini untuk memberikan gambaran perhitungan jumlah kopi yang dapat dikonsumsi dan berat badan seseorang.
\end{abstract}

Kata kunci: Aplikasi Mobile, Komputasi Kaffein, Kopi Joss, Kopi, Kafein. 


\section{PENDAHULUAN}

Kopi adalah salah satu minuman yang paling banyak dikonsumsi di Dunia (Imatoh, et al., 2011). Data dari Asosiasi Eksportir dan Industri Kopi Indonesia mencatat bahwa kebutuhan pada tahun 2015 diperkirakan meningkat menjadi 280 juta kilogram dari tahun 2014, perkiraan 260 juta kilogram kopi dalam satu tahun (Fadah \& Handriyono, 2015). Kopi dapat digolongkan sebagai minuman psikostimulantyang akan menyebabkan orang tetap terjaga, mengurangi kelelahan, dan membuat perasaan menjadi lebih tenang (Putri \& Latunra, 2013). Kopi memiliki asam klorogenat yang merupakan antioksidan dominan yang ada dalam biji kopi yaitu berupa ester yang terbentuk dari asam transsinamat dan asam quinat (Ramalakshmi \& Raghavan, 2000).

Kopi adalah sumber utama kafein seluruh dunia (Ruusunen, et al., 2010). Kafein adalah salah satu psikoaktif yang digunakan untuk mengurangi kelelahan dan juga menghilangkan kantuk (Ruusunen, et al., 2010). Kafein pada kopi digunakan untuk merangsang susunan saraf pusat dan otot jantung, dapat menyebabkan diuresis serta melemaskan otot polos bronchus. Dalam dosis standar 50-200 mg, kafein utamanya mempengaruhi lapisan luar otak.

\section{METODE PENELITIAN}

\section{Bahan Penelitian}

Bahan yang dibutuhkan dalam penelitian adalah berupa data primer dan data sekunder. Data primer diperoleh lewat wawancara dengan pihak terkait dan pengamatan langsung, sedangkan data sekunder diperoleh lewat pengumpulan
Pengaruh ini bisa mengurangi kelelahan (Putri \& Latunra, 2013).

Konsumsi kafein yang umum antara anak-anak dan pemuda untuk minuman seperti soda (30-55 mg kafein per $12 \mathrm{oz} /$ $355 \mathrm{ml}$ ) dan belakangan ini "minuman energi" memiliki konsentrasi kafein yang lebih tinggi yaitu (70-130 mg kafein per 12 oz / $355 \mathrm{ml}$ ) dari pada soda, dan dipasarkan khusus bagi orang-orang muda (Arria \& O'Brien, 2011). Sebagai perbandingan, biasa $1 \mathrm{oz} / 30 \mathrm{ml}$ kopi espresso mengandung 40$75 \mathrm{mg}$ kafein dan generic diseduh $12 \mathrm{oz} /$ $355 \mathrm{ml}$ cangkir kopi 145-250 mg kafein (Alfgeir, et al., 2013). Penjualan dan konsumsi minuman energi telah meningkat tajam selama terakhir dekade (Alfgeir, et al., 2013).

Penyajian kopi yang berbagai macam memberi variasi dan cita rasa kopi itu sendiri. Salah satu penyajian kopi yang khas adalah Kopi Joss yang berada di Daerah Istimewa Yogyakarta. Penyajian kopi hitam dengan memberikan bara arang di dalamnya. Arang dibakar di atas suhu tinggi, secara alami akan merubah arang menjadi karbon aktif yang berfungsi mengikat polutan dan racun yang ada dalam tubuh (Harish, et al., 2011). Arang atau karbon aktif sudah dikenal ampuh sebagai obat alami anti racun (Pirarat, et al., 2015).

naskah-naskah, dokumentasi atau laporan dari sumber data.

\section{Kerangka Penelitian}

Tahapan atau langkah - langkah penulis dalam melakukan penelitian digambarkan dengan menggunakan flowchart sistem seperti pada gambar 1 .

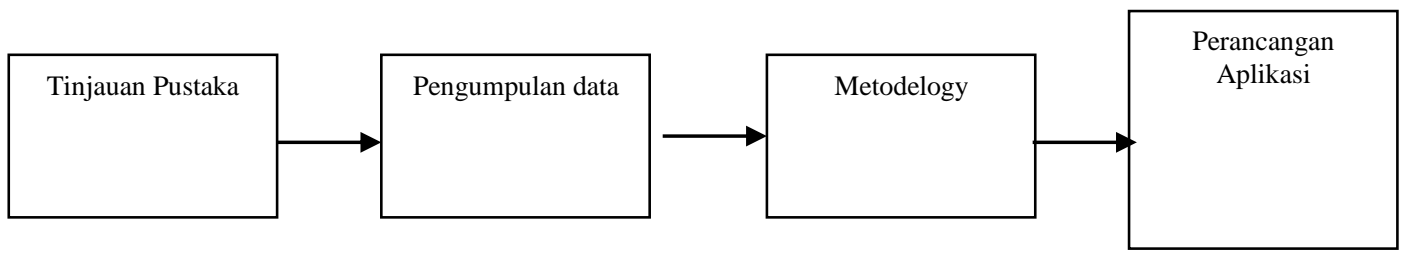

Gambar 1. Kerangka penelitian

\section{TINJAUAN PUSTAKA}

Komputer modeling telah berhasil di terapkan pada dunia kesehatan, seperti perhitungan kadar oksigen pada air, dan juga untuk melakukan perhitungan kualitas udara. (Jiang, et al. 2012), (Yang, et al. 2013), (Wang, et al. 2014), (Isakov, et al. 2014). Penelitian sebelumnya telah banyak 
membahas mengenai konsumsi makanan dan minuman yang mengandung kafein seperti teh, soda, kopi, dan minuman energy (Alfgeir, et al. 2013), (Arria and O’Brien 2011). Penelitian yang telah membahas jumlah konsumsi kafein yang ideal dalam sehari. sudah dilakukan (Rudolph, Faerbinger and Koenig 2014). Dari tinjauan pustaka yang ada maka diusulkan penelitian yang bertujuan untuk menghitung jumlah ideal konsumsi kopi joss berdasarkan berat badan seseorang.

\section{Pengumpulan Data}

Pada tahap ini dilakukan dengan dua cara, yaitu:

1. Wawancara atau tanya jawab yang digunakan sebagai data primer. Wawancara dan Tanya jawab dilakukan kepada beberapa penjual kopi joss dan juga pembeli kopi jos yang berada di sekitar malioboro.

2. Pengumpulan data-data yang diambil dari studi pustaka terhadap topic penelitian seperti jurnal, prosiding dan juga buku.

\section{Metodelogy}

Arang diakui sebagai pengikat obat dan zat beracun lainnya dari saluran pencernaan dan telah digunakan dalam pengobatan sejak zaman kuno (Pirarat, et al. 2015). Arang aktif adalah obat penawar universal untuk sebagian besar racun (Alkhatib and Khalid 2015). Penggunaan arang aktif untuk mengobati keracunan dikenal sejak 1830 oleh kimiawan bertrand Perancis (Alkhatib and Khalid 2015).Arang aktif dihasilkan melalui proses pirolisis bahan yang mengandung karbon dan diaktifkan oleh oksidasi dengan uap pada suhu tinggi. Arang aktif memiliki luas permukaan sekitar $1000 \mathrm{~m} 2 / \mathrm{g}$ dan memiliki kemampuan untuk menyerap banyak obat. (Harish, et al. 2011).

Kandungan kafein dalam minuman dan makanan meningkat di hal dosis dan ketersediaan, dengan perkiraan terbaru total. Konsumsi kafein harian menunjukkan bahwa rata-rata orang mengkonsumsi 180,94 mg sampai dangan 319,32 mg kafein per hari (Drake, et al. 2013). Untuk mengetahui jumlah cafeein pada kopi dilakukan ekstraksi kafein dari teh dan kopi dengan menggunakan kloroform sebagai pelarut ekstraksi (S, Rameshaiah and Ashoka 2015).

Tabel 1. Kafein dari teh dan kopi (S, Rameshaiah and Ashoka 2015)

\begin{tabular}{|l|l|l|l|}
\hline Sl.no & Sample & \multicolumn{1}{|c|}{ Amt of sample(g) } & \multicolumn{1}{c|}{$\begin{array}{c}\text { Amt of caffeine after solvent } \\
\text { extraction(g) }\end{array}$} \\
\hline 1. & Tea & 5 & 0. \\
\hline 2. & Coffee & 5 & 0.252 \\
\hline
\end{tabular}

Rumus : Kadar kafein $=\frac{\text { massa } \text { kafein }}{\text { berat awal }} \times 100 \%$

Rumus perhitungan persentase cafeein ( $\mathrm{S}$, Rameshaiah and Ashoka 2015)

Asupan kafein secara bw untuk setiap hari dalam sampel dihitung menjadi 5,3 mg / $\mathrm{kg}$ bb per hari, asupan rata-rata adalah 3,7 $\mathrm{mg} / \mathrm{kg}$ bb per hari (Rudolph, Faerbinger and Koenig 2014). 
Table 2.Consumption of foods and beverages contributing to caffeine intake and resulting caffeine intake $(n=700)$, all consumers (Rudolph, Faerbinger and Koenig 2014).

\begin{tabular}{|c|c|c|c|c|c|c|c|c|c|}
\hline \multirow[t]{2}{*}{ Food category } & \multicolumn{4}{|c|}{ Food intake ( $\mathrm{ml} / \mathrm{g}$ per day) } & \multirow[b]{2}{*}{$\mathrm{n}^{*}$} & \multicolumn{4}{|c|}{ Caffeine intake (mg per day) } \\
\hline & Mean & s.d. & Median & 95 percentile & & Mean & s.d. & Median & 95 percentile \\
\hline Coffee total & 485.0 & 593.1 & 400.0 & 1382.3 & 520 & 217.3 & 313.1 & 160.0 & 677.6 \\
\hline Ice coffee & 36.4 & 119.0 & 0.0 & 228.2 & 222 & 9.1 & 29.7 & 0.0 & 57.1 \\
\hline Tea & 53.5 & 160.3 & 0.0 & 400.0 & 185 & 13.1 & 31.1 & 0.0 & 68.6 \\
\hline Ice tea & 298.3 & 565.9 & 49.3 & 1250.0 & 404 & 14.9 & 28.3 & 2.5 & 62.5 \\
\hline Colas & 343.2 & 481.7 & 148.3 & 1285.7 & 542 & 33.8 & 46.2 & 15.7 & 130.0 \\
\hline Energy drinks & 133.9 & 271.9 & 35.7 & 500.0 & 432 & 42.6 & 90.1 & 11.4 & 160.0 \\
\hline Energy shots & 0.4 & 4.8 & 0.0 & 0.0 & 17 & 0.6 & 7.3 & 0.0 & 0.0 \\
\hline Coffee-based beverages and cocoa & 60.5 & 187.7 & 0.0 & 464.3 & 166 & 9.1 & 28.2 & 0.0 & 69.6 \\
\hline Chocolate & 43.4 & 108.6 & 13.8 & 158.2 & 537 & 7.8 & 19.6 & 2.5 & 28.5 \\
\hline Coffee-based foods & 15.9 & 69.4 & 0.0 & 114.3 & 100 & 0.6 & 2.8 & 0.0 & 4.6 \\
\hline Other foods & 0.8 & 6.7 & 0.0 & 0.0 & 32 & 0.4 & 3.3 & 0.0 & 0.0 \\
\hline Drugs, pills (no. per day) & 0.2 & 0.8 & 0.0 & 0.4 & 328 & 8.1 & 35.1 & 0.0 & 21.4 \\
\hline Total caffeine intake (mg per day) & & & & & & 357.4 & 400.4 & 258.5 & 957.2 \\
\hline Total caffeine intake $(\mathrm{mg} / \mathrm{kg} \mathrm{bw})$ & & & & & & 5.33 & 5.98 & 3.7 & 14.46 \\
\hline
\end{tabular}

Penelitian yang diusulkan pengembangan aplikasi mobile untuk perhitungan konsumsi kopi joss perharinya. Untuk melakukan perhitungan kafein terhadap kopi joss sebelumnya dilakukan extraksi jumlah cafeein untuk mengetahui jumlah cafeein pada kopi (S, Rameshaiah and Ashoka 2015). Extraksi dilakukan dengan menggunakan kloroform sebagai pelarut ekstraksi (S, Rameshaiah and Ashoka 2015). Setelah melakukan extraksi didapatkan jumlah caffeine dalam $5 \mathrm{~g}$ kopi mengandung $0.252 \mathrm{~g}$ cafeein.

\section{Perencanaan Aplikasi}

Aplikasi ini direncanakan untuk berjalan di smartphone dengan sistem operasi android. Menu-menu yang dirancang adalah :

1. Perhitungan Konsumsi Kopi Joss

2. Komputasi Kafein.

3. Berkenaan.

4. Bantuan

Menu aplikasi tersebut yang akan di tampilkan dalam perancangan aplikasinya seperti pada gambar 1

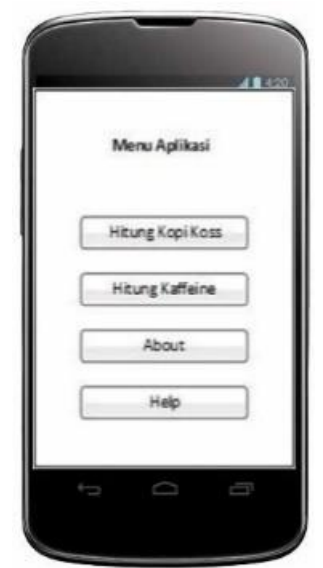

Gambar 2. Menu Aplikasi

\section{HASIL DAN PEMBAHASAN}

Kopi joss menggunakan sedok teh untuk takaran, komposisi kopi bubuk yang digunakan kopi joss adalah 2 sendok teh bubuk kopi. Untuk melakukan perhitungan terhadap jumlah kafein pada kopi joss menggunakan persamaan :

1 sendok teh kopi $=4$ gram kopi.

2 sendok teh kopi $\mathrm{x} 4$ gram $=8$ gram kopi

5 gram kopi $=0.252$ gram kaffein
1 gram kopi $=0.252 / 5=0.0504$ gram kaffeine

8 gram kopi x 0.0504 gram kafein $=0.4032$ gram kafein.

0.4032 gram diubah ke milligram $=403 \mathrm{mg}$

Jadi dalam satu porsi kopi joss terdapat $403 \mathrm{mg}$ kaffein, setelah ditemukan jumlah kafein dalam kopi joss maka 
selanjutnya melakukan jumlah maksimal

konsumsi kafein berdasarkan berat badan.

Table 3. Consumption of foods and beverages contributing to caffeine intake and resulting caffeine intake ( $\mathrm{n}=700)$, all consumers (Rudolph, Faerbinger and Koenig 2014).

\begin{tabular}{|c|c|c|c|c|c|c|c|c|c|}
\hline \multirow[t]{2}{*}{ Food category } & \multicolumn{4}{|c|}{ Food intake ( $\mathrm{ml} / \mathrm{g}$ per day) } & \multirow[b]{2}{*}{$\mathrm{n}^{*}$} & \multicolumn{4}{|c|}{ Caffeine intake (mg per day) } \\
\hline & Mean & s.d. & Median & 95 percentile & & Mean & s.d. & Median & 95 percentile \\
\hline Coffee total & 485.0 & 593.1 & 400.0 & 1382.3 & 520 & 217.3 & 313.1 & 160.0 & 677.6 \\
\hline Ice coffee & 36.4 & 119.0 & 0.0 & 228.2 & 222 & 9.1 & 29.7 & 0.0 & 57.1 \\
\hline Tea & 53.5 & 160.3 & 0.0 & 400.0 & 185 & 13.1 & 31.1 & 0.0 & 68.6 \\
\hline Ice tea & 298.3 & 565.9 & 49.3 & 1250.0 & 404 & 14.9 & 28.3 & 2.5 & 62.5 \\
\hline Colas & 343.2 & 481.7 & 148.3 & 1285.7 & 542 & 33.8 & 46.2 & 15.7 & 130.0 \\
\hline Energy drinks & 133.9 & 271.9 & 35.7 & 500.0 & 432 & 42.6 & 90.1 & 11.4 & 160.0 \\
\hline Energy shots & 0.4 & 4.8 & 0.0 & 0.0 & 17 & 0.6 & 7.3 & 0.0 & 0.0 \\
\hline Coffee-based beverages and cocoa & 60.5 & 187.7 & 0.0 & 464.3 & 166 & 9.1 & 28.2 & 0.0 & 69.6 \\
\hline Chocolate & 43.4 & 108.6 & 13.8 & 158.2 & 537 & 7.8 & 19.6 & 2.5 & 28.5 \\
\hline Coffee-based foods & 15.9 & 69.4 & 0.0 & 114.3 & 100 & 0.6 & 2.8 & 0.0 & 4.6 \\
\hline Other foods & 0.8 & 6.7 & 0.0 & 0.0 & 32 & 0.4 & 3.3 & 0.0 & 0.0 \\
\hline Drugs, pills (no. per day) & 0.2 & 0.8 & 0.0 & 0.4 & 328 & 8.1 & 35.1 & 0.0 & 21.4 \\
\hline Total caffeine intake (mg per day) & & & & & & 357.4 & 400.4 & 258.5 & 957.2 \\
\hline Total caffeine intake $(\mathrm{mg} / \mathrm{kg} \mathrm{bw})$ & & & & & & 5.33 & 5.98 & 3.7 & 14.46 \\
\hline
\end{tabular}

Seperti terlihat pada tabel 1, jumlah maksimal kafein adalah $5.33 \mathrm{mg}$ dalam sehari. Maka persamaan yang di dapat untuk melakukan perhitungan adalah.

\section{Komputasi Kopi Joss}

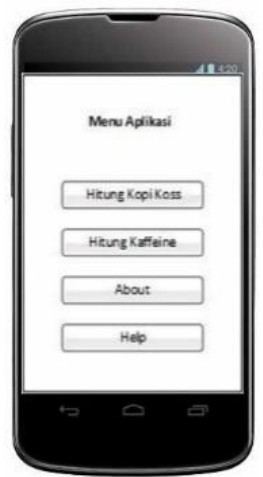

Gambar 3. Menu Aplikasi

Komputasi Kaffeine merupakan perhitungan yang dapat dibuat untuk mengetahui jumlah kaffein yang di dapat dari kopi joss. Setelah mengetahui jumlah kaffein yang terdapat dalam kopi joss, selanjutnya dilakukan perhitungan maksimal konsumsi kopi joss berdasarkan berat badan. Gambar merupakan rancangan aplikasinya.

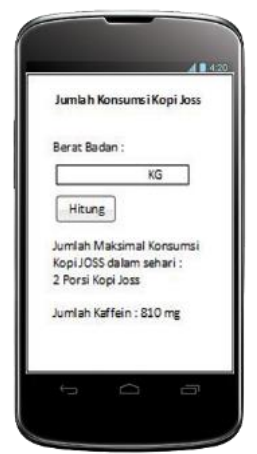

Gambar 4. Komputasi Kopi Joss

Perhitungan jumlah caffeine dan juga jumlah maksimal konsumsi kopi joss berdasarkan berat badan menggunakan rumus sebagai berikut. $\mathrm{x}=\mathrm{a} \times 5.33 \mathrm{mg}$ caffeine 
$\mathrm{x}=75 \mathrm{~kg} \mathrm{x} 5.33 \mathrm{mg}$

$\mathrm{x}=399.75 \mathrm{mg}$

penjelasan :

$\mathrm{x}=$ jumlah maksimal konsumsi caffeine perhari berdasarkan berat badan.

$\mathrm{a}=$ berat badan .

jadi jumlah maksimal konsumsi

caffeine perhari berdasarkan berat badan seseorang $75 \mathrm{~kg}$ adalah sebanyak $399.75 \mathrm{mg}$ caffeine dalam sehari. Setelah mendapatkan jumlah maksimal konsumsi caffeine, selanjutnya mencari jumlah caffeine yang terdapat dalam satu porsi kopi joss.

1 sendok teh kopi $=4$ gram kopi.

2 sendok teh kopi $\mathrm{x} 4$ gram $=8$ gram kopi

5 gram kopi $=0.252$ gram kaffein

1 gram kopi $=0.252 / 5=0.0504$ gram kaffeine
8 gram kopi x 0.0504 gram kafein $=0.4032$ gram kafein.

0.4032 gram diubah ke milligram $=403 \mathrm{mg}$ Untuk mencari jumlah maksimal konsumsi kopi joss berdasarkan porsi kopi joss.

$\mathrm{W}=\mathrm{x} / 403$

$\mathrm{W}=399.75 / 403$

$\mathrm{W}=1$

Jadi jumlah maksimal seseorang dengan berat badan $75 \mathrm{~kg}$ adalah 1 porsi kopi joss dalam sehari.

\section{Komputasi Kaffeine}

Komputasi kalori digunakan untuk menentukan jumlah caffeine dalam kopi berdasarkan berat bubuk kopi dalam satuan gram. Berikut adalah tampilan komputasi caffeine dalam smart phone.

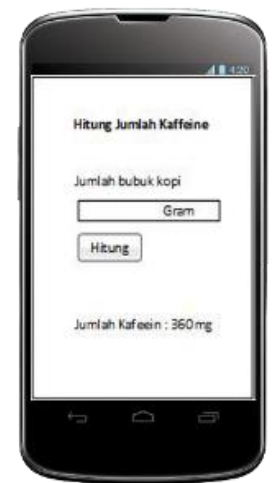

Gambar 5. Komputasi Caffeine

Untuk melakukan perhitungan komputasi mencari jumlah caffeine dalam kopi dengan satuan gram adalah.

5 gram kopi $=0.252$ gram kaffein

1 gram kopi $=0.252 / 5=0.0504$ gram

kaffeine
8 gram kopi $\mathrm{x} 0.0504$ gram kafein $=0.4032$ gram kafein.

Tabel 4. Perbandingan Porsi Kopi Joss

\begin{tabular}{|c|c|c|}
\hline Bodyweight & $\begin{array}{c}\text { Max Caffeine Quantity } \\
(\mathbf{m g} / \mathbf{k g ~ B W})\end{array}$ & Portion of Kopi Joss \\
\hline 50 & 266.5 & 0.66 \\
\hline 60 & 319.8 & 0.79 \\
\hline 75 & 399.75 & 0.99 \\
\hline 80 & 426.4 & 1.06 \\
\hline 100 & 426.4 & 1.06 \\
\hline
\end{tabular}

Dari hasil diatas seseorang dapat dengan cepat mengetahui jumlah kopi joss yang boleh dikonsumsi dalam sehari. Dimana nantinya seseorang yang ingin menjaga kesehatan badan dapat dengan mudah mengetahui jumlah kopi joss yang dapat dikonsumsi dalam sehari. Dimana dengan hanya menginputkan berat badan, 
maka sesorang dapat mengetahui jumlah kopi joss yang dapat dikonsumsi.

\section{Bantuan}

Dalam menu bantuan ini berisi informasi bantuan penggunaan untuk menumenu aplikasi dan langkah-langkah penggunaan aplikasi. Pada menu batuan dijelaskan langkah pertama yang harus dilakukan adalah:

1. Apa saja yang harus diinputkan user pada halaman komputasi kopi joss dan apa output nya.

2. Selanjutnya yaitu komputasi caffeine, pada menu ini akan dijelaskan apa yang harus dinputkan user dan dalam satuan apa.

\section{DAFTAR PUSTAKA}

[1]. Alfgeir, L, Kristjansson, Inga Dora Sigfusdottir, Stephanie S. Frost, and Jack E. James. (2013). Adolescent Caffeine Consumption and Self-Reported Violence. Journal Youth Adolescence.

[2]. Arria, A. M, and O'Brien. (2011). The " "high" risk of energy.Journal of the American Medical Association.

[3]. Drake, Christopher, Timothy Roehrs, John Shambroom, and Thomas Roth. (2013). Caffeine Effects on Sleep Taken 0, 3, or 6 Hours before Going.Journal of Clinical Sleep Medicine, 195-1200.

[4]. Fadah, Isti, and Handriyono. (2015). The Performance Improvement Model of Group and Partnership based Coffee Processing Enterprises in the Jember Regency.Journal of Social and Development Sciences, 7-13.

[5]. Harish, Dasari, K H Chavali, Amandeep Singh, and Ajay Kumar. (2011). Recent Advances in the Management of Poisoning Cases.J Indian Acad Forensic Med, 73-39.

[6]. Imatoh, T, S Tahihara, M Miyazaki, Y Momose, and Y Uryu. (2011). Coffee consumption but not green tea consumption is associated with adiponectin levels in Japanese males.European Journal of Nutrition, 279-84.

[7]. Isakov, Vlad, Saravanan Arunachalam, Stuart Batterman, Sarah Bereznicki, and Janet Burke. (2014). Air Quality Modeling in Support of the Near-Road Exposures and Effects of Urban Air Pollutants Study

\section{SIMPULAN}

Dari uji coba yang telah dilakukan maka dapat diambil kesimpulan perhitungan untuk menentukan jumlah caffeine maksimal yang dibuthkan oleh tubuh berhasil diketahui dan selanjutnya digunakan unutk melakukan perhitungan ideal jumlah konsumsi kopi joss. Pengambangan aplikasi mobile ini dapat membantu user untuk menjaga jumlah komsumsi caffeine khususnya pada kopi joss.

(NEXUS).International Journal of

Environmental Research and Public Health.

[8]. Jiang, Zhiwei, Ling Wang, Chanjuan Li, Jielai Xia, and Hongxia Jia. (2012). A Practical Simulation Method to Calculate Sample Size of Group Sequential Trials for Time-to-Event Data under Exponential and Weibull Distribution: e44013.PLoS One.

[9]. Olusegun, Onabajo Olawale, and Chong Eng Tan. (2013). Location-based Solar Energy Potential Prediction Algorithm for Mountainous Rural Landscapes.International Journal of Computer Science and Information Security, 5-12.

[10]. Pirarat, Nopadon, Surinton Boonananthanasarn, Laddawan Krongpong, and Takayuki Katagiri. (2015). Effect of Activated Charcoal-Supplemented Diet on Growth Performance and Intestinal Morphology of Nile Tilapia (Oreochromis niloticus).The Thai Journal of Veterinary Medicine, 113-119.

[11]. Putri, WIrabuana, and Andi Ilham Latunra. (2013). Kandungan Kafein dan Polifenol Pada Biji Kopi Arabika Coffea Arabica L. Dari Kabupaten Enrekang.Jurnal Alam dan Lingkungan, 50-62.

[12]. Ramalakshmi, K, and B Raghavan. (2000). Caffeine in Coffee : Its Removal. Why and How? Critical.Reviews in Food Science and Nutrition, 441.

[13]. Rudolph, E, A Faerbinger, and J Koenig. (2014). Caffeine intake from all sources in adolescents and young.European Journal of Clinical Nutrition, 793-798. 
[14]. Ruusunen, Anu, Soili M Lehto, Tommi Tolmunen, Jaakko Mursu, George A Kaplan, and Sari Vautilainen. (2010). Coffee, Tea and Caffeine intake and the risk of severe depression in middle-aged Finnish men : the Kuopio Ischaemic Heart Disease Risk Factor Study.Public Health Nutrition, 1215-1220.

[15]. S, Pradeep, G N Rameshaiah, and Hadagali Ashoka. (2015). CAFFEINE EXTRACTION AND CHARACTERIZATION.International Journal of Current Research and Review, 7 (9): 16-19.
[16]. Wang, Chao, Baoqing Shan, Hong Zhang, and Nan Rong. (2014). Analyzing sediment dissolved oxygen based on microprofile modeling.Environmental Science and Pollution Research International.

[17]. Yang, Hongmei, Susan Duvall, Amy Ratcliffe, David Jeffries, and Warren Stevens. (2013). Modeling health impact of global health programs implemented by Population Services International.BMC Public Health. 